\title{
Burden of combined obesity among students of a medical college in Guntur city of Andhra Pradesh
}

\author{
Sree M. S. ${ }^{\mathbf{1}}$, Dampetla S. ${ }^{2 *}$ \\ DOI: https://doi.org/10.17511/ijphr.2019.i3.02 \\ ${ }^{1}$ Santhi Sree M., Department of Community Medicine, Ananta Institute of Medical Sciences and Research Centre, Rajsamand, Rajasthan, \\ India. \\ 2* Srujana Dampetla, Department of Physiology, Guntur Medical College, Guntur, Andhra Pradesh, India.
}

\begin{abstract}
Background: Obesity is a major public health problem especially in adolescent age group. Obesity is now recognized as a chronic or non-communicable disease. Medical students are not an exception to this fast spreading epidemic, despite their medical knowledge. Few studies in fact have reported higher prevalence among medical fraternity than general population. Also, based on scientific evidence of higher proportion body fat than muscle mass among Asian Indians, the actual prevalence may be higher than what is assessed by WHO cut off for BMI. In some cases central obesity is very high in individuals whom the BMI is normal. Both BMI and WC in combination would be better predictors of obesity related diseases than sole using of BMI or WC alone. Very limited knowledge is available on combined obesity. So, we planned this study to know its burden especially among medical students. Methodology: It was a cross-sectional study at a medical college in Andhra Pradesh. A total of 207 medical students were selected from first and third semesters by simple random selection. Data was collected on sociodemographic data and the data of height and weight (BMI, General obesity), waist circumference (Central obesity). Finally, we estimated the burden of combined obesity (BMI+C.O). Results: It was observed that $35(16.91 \%)$ medical students were having combined obesity (obesity according to BMI and waist circumference G.O + C.O). Among them $15(20 \%)$ are male, and $20(15.15 \%)$ are female students. Conclusions: The present study gives an idea about the high prevalence of combined obesity in the medical students. This should be an alert signal because medical students are the future doctors, health leaders and role models to the community. So, we need to identify specific barriers among medical students and come up with workable solutions.
\end{abstract}

Keywords: BMI, Central Obesity, Combined Obesity, General Obesity, Medical Students

Corresponding Author

Srujana Dampetla, Department of Physiology, Guntur Medical College, Guntur, Andhra Pradesh, India. Email: drsanthisree@gmail.com
How to Cite this Article

Sree MS, Dampetla S. Burden of combined obesity among students of a medical college in Guntur city of Andhra Pradesh. Public Health Rev Int J Public Health Res. 2019;6(3):105-111.

Available From

https://publichealth.medresearch.in/index.php/ijphr/ article/view/107
To Browse

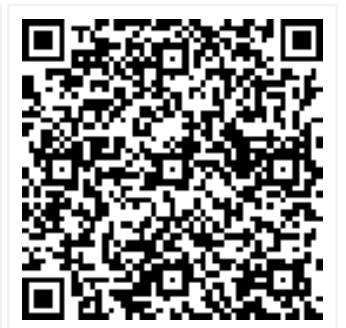

Manuscript Received 2019-05-16

Conflict of Interest No
Review Round 1 2019-05-26

Funding $\mathrm{Nil}$

Review Round 2
2019-06-02
$\begin{gathered}\text { Ethical Approval } \\ \text { Yes }\end{gathered}$

Review Round 2

Yes
Review Round 3

Plagiarism X-checker $8 \%$
Accepted 2019-06-06

(c) 2019 by Santhi Sree M., Srujana Dampetla and Published by Siddharth Health Research and Social Welfare Society. This is an Open Access article licensed under a Creative Commons Attribution 4.0 International License https://creativecommons.org/licenses/by/4.0/ unported [CC BY 4.0]. 


\section{Introduction}

Background: Obesity is a major public health problem especially in adolescent age group. Obesity is now recognized as chronic non-communicable disease [1]. Medical students are also not an exception to come under this over weight and obesity category in spite of their medical knowledge. Stress is the major factor which contributes to obesity [2].

Medical education is highly stressful so majority of the students are having irregular unhealthy lifestyle. Due to the pressure of examinations and lack of coping skills medical students have irregular dietary habits. Medical students need to be extra conscious about overweight and obesity because its prevalence was found as high among them.

This obesity and overweight is a major risk factor for non-communicable diseases and co morbidities [3-4]. In Asian Indians evidence show that body fat is more than muscle mass. According to WHO cut off for BMI in non obese are actually obese when body fat taken into consideration [5]. In some cases central obesity is very high in individuals whom the BMI is normal which has been termed "metabolically obese" [6].

Studies shows that in The Asian Indians body fat composition is high compared to muscle mass which is the main cause for metabolic obesity. Some Indians considered non-obese by the WHO criteria of BMI cut-offs are actually obese when body fat is used to define obesity. Secondly there is a high prevalence of abdominal adiposity even in people who are otherwise considered as non-obese [7-8-9].

Central obesity is important risk factor for cardiac risk than compared to general obesity. Waist circumference is simple and easily obtainable measurement for central obesity [10-11].

In many studies BMI has taken as important parameter for obesity, but in few studies waist circumference has taken into consideration. In our study we have taken both BMI and WC combined obesity which is a potential risk factor for many diseases especially non-communicable diseases.

So this study was done with the aim to estimate the prevalence of central obesity combined with high Body Mass Index among the undergraduate medical students.

Objectives of the study: The primary objective
Was to assess the burden of central obesity combined with high Body Mass Index among medical students.

\section{Methodology}

Study setting: The current study was conducted in a tertiary care teaching hospital in Andhra Pradesh

Study duration: Study was conducted for a period of twelve months in the year 2018 including study design, approval and data acquisition and analysis

Study type: Cross-sectional study

Sampling methods: We have selected 207 medical students from first and third semesters by simple random selection.

Inclusion criteria: First and third semester students of MBBS were included in the study.

Exclusion criteria: if the student was suffering from any psychiatric illness or under any antidepressant medications they were excluded from the study.

Data collection procedure: Data was collected using a structured data collection tool, comprising of self-administered close ended questionnaire on key demographic variables. The tool also had details regarding the anthropometric parameters like weight, height, waist circumference.

Initially data on self-administered questionnaire was collected in the class room, after making them seated at sufficient distance to avoid discussion and exchange of information. Later anthropometric measurements were done at the end of practical or clinical posting sessions.

Height was recorded with stature meter, while individuals stood straight with their heels, buttocks and scapula rest against a wall. Waist circumference (WC) was measured using a flexible non-elastic measuring tape. Individuals stood with their feet together, arms resting by their side.

Waist circumference was measured at the approximate midpoint between the lower margin of the last palpable rib and the top of the iliac crest according to WHO STEPS protocol [12].

The BMI was calculated using the Quetelet's equation (ratio of weight in $\mathrm{kg}$ and square of height in $\mathrm{m}$ ). BMI cut off values for Indians to define overweight and obesity taken from WHO. Participants with waist circumference value higher 
Than gender specific waist circumference cut off values (90 cm for males and $80 \mathrm{~cm}$ for females) were considered to central obesity. People with both higher BMI and higher than gender specific cut off value of waist circumference were considered as central obesity [5].

Data analysis: Data was compiled in Excel sheet and later analysed with SPSS Statistics version 21. Quantitative variables were summarized as mean and standard deviation; categorical variables were summarized as frequencies and percentages.

Association between quantitative variables was assessed by Pearson correlation coefficient. P Value $<0.05$ will be considered as statistically significant.

Ethical consideration and permission: Study was commenced after Institutional ethical committee approval. Written informed consent was obtained from the participants before initiation of the study.

\section{Results}

A total of 207 students were included in the final analysis. Among 207 students, males were 75 (36.23\%), females $132(63.77 \%)$, hostellers 73 $(35.3 \%)$, day scholars $134(64.7 \%)$.

Family history nil for NCD's in 60 (29\%), in 61 $(29.5 \%)$ one lifestyle diseases was present, in 86 students $(41.5 \%)$ more than one problem present for e.g. either hypertension, or diabetes or CAD.

Among 207 students $62(29.9 \%)$ are not involved in any sort of exercise, $54(26.1 \%)$ students were doing 30 minutes per day, $85(41.1 \%)$ students were involved in sports for more than 30 minutes per day.

Time spending with TV music up to one hour seen in maximum number of students $117(56.5 \%), 17$ students (8.2\%) watching for 3 hours and more than 3 hours per day. Mobile usage of up to 1 hour seen in $125(60.4 \%)$ students, maximum of 3 hours and more seen in $33(15.9 \%)$ students (Table 1$)$.

Table-1: Characteristics of the study population $(\mathrm{N}=207)$.

\begin{tabular}{|l|l|}
\hline \multicolumn{2}{|c|}{ Parameter } \\
\hline Gender & N (\%) \\
\hline Male & $132(63.77 \%)$, \\
\hline Female & $73(35.3 \%)$, \\
\hline Place of residence & \\
\hline Hostel
\end{tabular}

\begin{tabular}{|l|l|}
\hline Day scholar & $134(64.7 \%)$ \\
\hline Socio economic status & $52(25.11 \%)$ \\
\hline below Rs.40,000 & $120(58.0 \%)$ \\
\hline Rs.40,000 to Rs.1 lakh & $35(16.9 \%)$ \\
\hline more than 1lakh & \multicolumn{2}{|l|}{} \\
\hline Family history of NCD & $60(29 \%)$ \\
\hline Nil & $61(29.5 \%)$ \\
\hline One & $86(41.5 \%)$ \\
\hline More than 1 NCD & $62(29.9 \%)$ \\
\hline Physical activity & $6(2.9 \%)$ \\
\hline Nil & $54(26.1 \%)$ \\
\hline 10 to 20 mints per day & $85(41.1)$ \\
\hline 30 mints per day & $11(5.3 \%)$ \\
\hline More than 30 minutes per day & $117(56.5 \%)$ \\
\hline Spending with TV & $79(38.2 \%)$ \\
\hline Nil & $125(60.4 \%)$ \\
\hline Up to 1 hour & $49(23.7)$ \\
\hline More than 1 hour & $33(15.9 \%)$ \\
\hline Mobile phone usage & \\
\hline 1 hour seen in & \\
\hline$>1$ hour to $<3$ hours & \\
\hline 3 hours and more & \\
\hline
\end{tabular}

Table-2: Prevalence of Obesity as per different criteria.

\begin{tabular}{|l|l|l|l|}
\hline Obesity & Male (N=75) & \multicolumn{1}{|c|}{ Female (N=132) } & \multicolumn{1}{|c|}{ Overall (N=207) } \\
\hline \multicolumn{5}{|c|}{ Obesity (As per BMI) } \\
\hline Yes & $22(29.33 \%)$ & $27(20.45 \%)$ & $49(23.67 \%)$ \\
\hline No & $53(70.67 \%)$ & $105(79.54 \%)$ & $158(76.33 \%)$ \\
\hline \multicolumn{5}{|c|}{ Obesity as per wC } \\
\hline Yes & $20(26.67 \%)$ & $34(25.76 \%)$ & $54(26.09 \%)$ \\
\hline No & $55(73.33 \%)$ & $98(74.24 \%)$ & $153(73.91 \%)$ \\
\hline \multicolumn{5}{|c|}{ Obesity Combined } \\
\hline Yes & $15(20 \%)$ & $20(15.15 \%)$ & $35(16.91 \%)$ \\
\hline No & $60(80 \%)$ & $112(84.85 \%)$ & $172(83.09 \%)$ \\
\hline
\end{tabular}

According to waist circumference 20 males $(26.67 \%)$ have central obesity (WC $>90 \mathrm{~cm}$ ), female students $34(25.76 \%)$ have central obesity (WC $>80 \mathrm{~cm}), 55(73.33 \%)$ male students and 98 (74.24\%) female students have waist circumference within normal limits (Table 2).

It was observed that $35(16.91 \%)$ medical students were having combined obesity (obesity according to BMI and waist circumference G.O + C.O). Among them $15(20 \%)$ are male, and $20(15.15 \%)$ are females (Table 2). 
Table-3: Correlation among different variables.

\begin{tabular}{|c|c|c|c|c|c|c|c|}
\hline \multicolumn{8}{|c|}{ Correlations } \\
\hline & & Waist Circumference & Exercise & Reading & Mobile & Physical Activity & TV and Music \\
\hline \multirow[t]{2}{*}{ Waist Circumference } & Pearson Correlation & 1 & $-0.292 * *$ & 0.083 & -0.023 & $-0.320 * *$ & 0.081 \\
\hline & Sig. (2-tailed) & - & 0.000 & 0.236 & 0.741 & 0.000 & 0.245 \\
\hline \multirow[t]{2}{*}{ Exercise } & Pearson Correlation & $-.292 * *$ & 1.0 & 0.077 & -0.008 & $0.723 * *$ & 0.032 \\
\hline & Sig. (2-tailed) & $<0.001$ & - & 0.269 & 0.910 & 0.000 & 0.642 \\
\hline \multirow[t]{2}{*}{ Reading } & Pearson Correlation & 0.083 & 0.077 & 1.0 & $-0.219 * *$ & $0.263 * *$ & $-0.168^{*}$ \\
\hline & Sig. (2-tailed) & 0.236 & 0.269 & - & 0.001 & 0.000 & 0.016 \\
\hline \multirow[t]{2}{*}{ Mobile } & Pearson Correlation & -0.023 & -0.008 & $-0.219 * *$ & 1 & 0.015 & 0.054 \\
\hline & Sig. (2-tailed) & 0.741 & 0.910 & 0.001 & - & 0.826 & 0.436 \\
\hline \multirow[t]{2}{*}{ Physical Activity } & Pearson Correlation & $-0.320 * *$ & $0.723^{* *}$ & $0.263^{* *}$ & 0.015 & 1 & 0.001 \\
\hline & Sig. (2-tailed) & $<0.001$ & $<0.001$ & $<0.001$ & 0.826 & - & 0.993 \\
\hline \multirow[t]{2}{*}{ TV \& Music } & Pearson Correlation & 0.081 & 0.032 & $-0.168^{*}$ & 0.054 & 0.001 & 1 \\
\hline & Sig. (2-tailed) & 0.245 & 0.642 & 0.016 & 0.436 & 0.993 & - \\
\hline
\end{tabular}

It was found significant $(P<0.001)$ positive correlation between BMI and Waist Circumference. There is significant $(P<0.001)$ negative correlation between Waist Circumference and exercise.

There is significant negative correlation between reading and mobile usage. TV viewing \& listening music also has significant negative correlation with reading (Table 3 ).

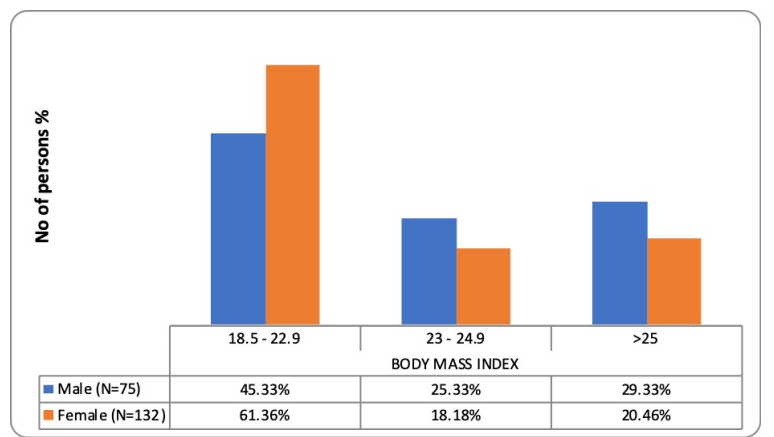

\section{Figure 1: Prevalence of overweight and obesity according to BMI}

According to BMI (WHO'S South East Asian guidelines) [13], 115 (55.56\%) students comes under normal weight (BMI 18.5 to 22.9), 43 $(20.77 \%)$ students comes under over weight (BMI= 23 to 24.9), 49 (23.67\%) students belongs to the category of general obesity (BMI > 25) (Figure 1).

\section{Discussion}

In this study among 207 students 43 (20.77\%) students are overweight and 49 (23.67\%) were obese according to BMI. Central obesity according to
Waist circumference observed in 54 (26.09\%) medicos. Combined obesity (BMI + C.O) is seen among 35 (16.91\%) medical students.

BMI and Waist circumference was positively correlated, means when BMI increasing waist circumference also increasing. Waist circumference is significantly correlated negatively with exercise or physical activity.

Similar study was conducted at Meenakshi Medical College hospital and research institute, Enathur, Kanchipuram district, Tamil Nadu, Out of 500 students, 458 (92\%) participated in the study [14]. $54 \%$ among them were males and $46 \%$ were females.

The prevalence of overweight was $24.3 \%$ and the prevalence of obesity according to BMI was $8.6 \%$ according to WHO guidelines [15]. Similar study conducted at BMCRI, Bengaluru, from JulySeptember 2014, in this study only BMI and waist circumference taken for estimating prevalence of obesity [16].

Out of the total 424 students studied, 62 (14.6\%) were overweight and $48(11.3 \%)$ were obese according to BMI. Risk factors like junk food, long hours of mobile and computer usages were taken. Out of 424 students studied, 47 males and 110 females making a sum of 157 (37\%) who was considered to have central obesity according to their waist circumference [16].

Another study done at Haryana among 130 MBBS students, normal BMI was observed in $73.1 \%$ 
Students, while $22.3 \%$ students were overweight, $3.1 \%$ obese [17]. A study was done at G.R medical college Gwalior among 131 second semester medical students.

In that study also BMI taken for overweight and obesity assessment and found the prevalence of overweight was $13(9.93 \%)$ and the prevalence of obesity was 2 (1.53\%). The prevalence of underweight was $25(19.08 \%)$ [18].

In this study we mainly concentrated on combined obesity which includes both BMI and waist circumference, which predicts more metabolic obesity. $20 \%$ of male students, $15.15 \%$ female students have combined obesity which is alarming.

Evidence suggests that the body composition abnormalities of Asian Indians may have an important bearing on the pathogenesis of metabolic derangements. First, their body fat is more and muscle mass less than compared with other Asian ethnic groups. Present day dietary habits, stressful routine lead to decreased physical activity is a primary drive of overweight and obesity.

Obesity leads to many medical consequences like hypertension, diabetes, coronary artery disease, stroke, and cancers. Psychological consequences are anxiety, depression, isolation, rejection, poor selfimage, and poor performance and the mechanical disturbances include osteoarthritis, abdominal hernia, diaphragmatic hernia, varicose veins.

Chronic obesity ultimately leads to increased insulin resistance, because of visceral fat which is a passive source of several hormones, cytokines and chemical signals to other tissues which can develop into type 2 diabetes. Central obesity is an important predictor of metabolic disorders than BMI [19].

Obesity is not only aetiology of many diseases it also affects the quality of life and finally leads to premature death [20]. Both BMI and WC in combination would be better predictors of obesity related diseases than sole using of BMI or WC alone [21].

Medical students in this study were in prepathogenesis phase or in latent period of noncommunicable diseases. The obesity problem can be reversible if we tackle them as early as possible through proper balanced diet, preventing sedentary lifestyle such as reducing TV watching time, promoting more physical activity and sports according to their interest and also coping skills for stress management.

\section{Conclusion}

The present study gives an idea about the high prevalence of overweight and obesity in the medical students. Obesity due to BMI and Waist circumference (Combined Obesity) in this study shows alarming situation in medical students. This study highlights that medicos though they are having knowledge about nutrition and physical activity could not be able to implement practically.

Students should focus on improving time management skill also they need to be encouraged to participate in physical exercise, especially sports, athletics, and other outdoor activities. Improvement in dietary habits, if made in early years of medical schooling, would produce physicians practicing and promoting healthy dietary habits. Awareness through health education was created to the medical students while measuring anthropometric measure-ments.

This should be an alert signal because medical students are the future doctors, health leaders and role models to the community. Further studies should be undertaken to identify specific barriers among medical students in practicing healthy dietary habits and come up with workable solutions. Therefore, it is of utmost importance to have early intervention programmes to prevent noncommunicable diseases among these future doctors.

\section{What this study adds to existing knowledge}

The study had highlighted the prevalence of different types of overweight and obesity among medical students. The key addition of the study was it's documentation of overall and central obesity and their overlap among the study population. The study highlights the importance assessing waist circumference, along with BMI, to avoid underestimation of the true burden of overweight and obesity.

\section{Author contribution}

Dr. SS had conceptualized the study, prepared the study protocol, and conducted the data collection, analysis and manuscript writing. She has verified all the drafts and approved the final draft. Dr. SD had provided key inputs on methodology during protocol preparation, supported data compilation and analysis. She has also edited all the drafts and 
Approved the final draft of the manuscript.

\section{Acknowledgements}

We express our sincere and heart full gratitude to the opportunity and support provided by the Dean of Katuri Medical College and Hospital Guntur (A.P). We are extremely thankful for the support provided by our faculties of Department of Community Medicine and Department of Physiology (GMC). Last but the most, we would like to thank all the MBBS students of first, and third semester of Katuri Medical College and Hospital for their cooperation, without whom this study would not be possible.

\section{Limitations}

First, the sample used in this study was a convenient sample and thus findings need to be interpreted with caution. Further qualitative studies are needed for better understanding to plan for interventions.

\section{Reference}

01. Rosen H. Is Obesity A Disease or A Behavior Abnormality?- Did the AMA Get It Right?. Mo Med. 2014 Mar-Apr;111(2)104-108.

[Crossref]

02. Verma K, Goyal S. Stress leading to overweight /obesity in First MB; BS hosteller girls. Int J Collab Res Intern Med Public Health. 2012;4(6)924-33.

[Crossref]

03. Shams N, Niaz F, Motwani R, Shaikh Z, Saleem F. Obesity and Hypertension in Female Medical Students; Frequency and Risk Factors. J Liaquat Uni Med Health Sci. 2015;14(01)26-32.

[Crossref]

04. Purohit G, Shah T, Harsoda JM. Prevalence of Obesity in Medical Students and its Correlation with Cardiovascular Risk Factors- Emergency Alarm for Today?. Kathmandu Univ Med J In Press. 2015;13(52)341-5.

[Article] [Crossref]

05. World Health Organization. Recommen-dationsObesity- Preventing and Managing the Global Epidemic. Geneva, Switzerland, World Health Org. 2000(WHO Technical Report Series No-894. Available from: [Article] [Crossref]
06. Snehalatha C, Viswanathan V, Ramachandran A. Cutoff values for normal anthropometric variables in asian Indian adults. Diabetes care. 2003;26(5)1380-4.

[Article] [Crossref]

07. Misra A. Body composition and the metabolic syndrome in Asian Indians- a saga of multiple adversities. Natl Med J India. 2003; JanFeb;16(1)3-7.

[Crossref]

08. Dudeja V, Misra A, Pandey RM, et al. BMI does not accurately predict overweight in Asian Indians in northern India. $\mathrm{Br} \mathrm{J}$ Nutr. 2001; Jul;86(1)105-12.

[Crossref]

09. Banerji MA, Faridi N, Atluri $R$, et al. Body composition, visceral fat, leptin, and insulin resistance in Asian Indian men. J Clin Endocrinol Metab. 1999 Jan;84(1)137-44.

DOI: $10.1210 /$ jcem.84.1.5371 [Crossref]

10. Sharma S, Raina SK, Bhardwaj AK, Chander V, Kumar D, Sharma S. Utility of Consensus Statement in Assessment of Obesity- A Study among Undergraduate Medical Students from Rural Northwest India. J Family Med Prim Care. 2013;2(3)274-6.

[Article] [Crossref]

11. Misra A, Chowbey P, Makkar BM, et al. Consensus statement for diagnosis of obesity, abdominal obesity and the metabolic syndrome for Asian Indians and recommendations for physical activity, medical and surgical management. J Assoc Physicians India. 2009 Feb;57;163-70.

[Crossref]

12. World Health Organization. Waist Circumference and Waist Hip Ratio- Report of a WHO Expert Consultation. Geneva, Switzerland- WHO. 2011. Available at: [Article] [Crossref]

13. World Health Organization. Recommen- dationsObesity- Preventing and Managing the Global Epidemic. Geneva, Switzerland, World Health Org. 2000 (WHO Technical Report Series No894.

[available at: [Article] [Crossref] 
14. Selvaraj K, Sivaprakasam P. A Study on the Prevalence of Overweight and Obesity among Medical Students of Kanchipuram District. NJRCM. 2013;2(2)140-4).

Available at: [Article] [Crossref]

15. World Health Organization. Regional Office for the Western Pacific (2000), The Asia-Pacific perspective- redefining obesity and its treatment. Sydney- Health Communications Australia. 2000.

Available at: [Article] [Crossref]

16. Gudegowda KS, Vengatesan S, Sobagiah RT. Prevalence of overweight and obesity among medical college students, Bengaluru. Int J Community Med Public Health. 2018;5;1881-6. [Article] [Crossref]

17. Yadav SS, Saini P, Khan ZA, Bachloo T, Kumar R, Singh J. Assessment of body mass index among undergraduate medical students- a crosssectional study from the Medical College of Haryana. Int J Med Sci Public Health. 2016;5;705-708.

[Article] [Crossref]
18. Tiwari R, Jain V, Rajput AS, Bhagwat AK, Goyal $M$, Tiwari S. A study to assess prevalence of obesity among medical students of GR medical college, Gwalior, M P, India. Int J Res Med Sci. 2014;2;1412-6.

[Article] [Crossref]

19. Adhikari A, Dey I, Mandal NK. A Study on Overweight \& Obesity and its Risk Factors among Undergraduate Students of a Medical College in Kolkata. J Comprehensive Health. 2015;3(2)42-51.

[Article] [Crossref]

20. R Parimalavalli, A Vijayalakshmi, S Radhai Sri. Anthropometric Profile and Nutrient Intake of Overweight/Obese Women. J Human Ecology. 2009;26(2)131-35.

[Article] [Crossref]

21. Anyanwu GE, Ekezie J, Danborno B, et al. Impact of education on obesity and blood pressure in developing countries- A study on the Ibos of Nigeria. N Am J Med Sci. 2010 Jul;2(7)320-4.

doi: $10.4297 /$ najms.2010.2320 [Crossref] 